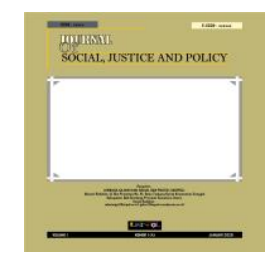

JOURNAL OF SOCIAL, JUSTICE AND POLICY

ISSN (ONLINE): 2809-8080

Volume 1 Number 1 January 2022

\title{
PERILAKU KEKERASAN DALAM BERPACARAN PADA MAHASISWA DI UNIVERSITAS SUMATERA UTARA
}

\author{
Rizky Aulia Khair $^{*}$, Agus Suriadi $^{1}$ \\ 1,2 Prodi Ilmu Kesejahteraan Sosial, Universitas Sumatera Utara. \\ Email Korespondensi: Rizkyaulia277@gmail.com \\ Email: agus4@usu.ac.id
}

\begin{abstract}
Conceptually, violence that occurs in the whole world with a various form is an indication of powerabuse, gender inequality and domination. Dating-Violence is an act of violence that against a partner, whether physical, sexual or psychological, that are committed before marriage. Nowadays, it is a problem that is quite prominent in the world community.The objectives of this research to obtain a more specific pictures of a dating-violence behaviour. The method of this research used a descriptivemethod using a qualitative approach. Descriptive research was conducted with the objectives of picturing or describing the object or phenomenon to be studied. The technique of this research was conducted using snowball sampling techniques. The samples in this research were Sekretaris Jenderal Pemerintahan Mahasiswa (PEMA). The student who experienced dating-violence at the Faculty of Social and Political Sciences, University of South Sumatera was the main sample of this research and another student, was her close-friend and families of students experiencing dating-violence. The data collection techniques using literature study, observation, and interviews. The data obtained and analysed by the researchers in order to found any new facts with a qualitative approach. The results of this research indicated that dating was no longer a matter of love and affection but rather someone tends to think that dating as a form of ownership not an exploratory process to get to know each other before stepping into a more serious step, namely marriage. Because of the opinion, it made a person committed violence to defend what was his/her own. The dating-violence were caused by several things, for examples: jealousy, infidelity, not obeying their couples' orders. The were two kinds of violence experienced in dating: verbal violence which is a psychological violence and non-verbal violence which is physical violence.
\end{abstract}

Keywords: Dating-Violence, College Students, Women

\section{Pendahuluan}

Pada masa saat mulai menjadi dewasa terutama di kalangan mahasiswa, baik perempuan dan laki-laki pasti sangat mengenal apa itu berpacaran atau menjalin hubungan. Pacaran merupakan suatu hubungan yang terjalin antara seorang laki-laki dan perempuan akibat adanya ketertarikan baik secara fisik maupun nonfisik yang dibangun diatas komitmen di antara keduanya (Safitri,2013) (dalam Lula An Naafi, 2015:1).

Berpacaran selalu dihadapkan pada situasi yang menuntut harus mampu menyesuaikan diri bukan hanya terhadap dirinya sendiri tetapi juga pasangannya. Pacaran memiliki dua dampak yaitu dampak positif dan negatif. Dampak positif dari pacaran adalah sebagai proses belajar untuk menjalin kebersamaan dan menjadi salah satu sarana dalam menyeleksi dan menemukan pasangan hidup (Santrock, 2003) (dalam Lula An Naafi, 2015:1). Sementara, untuk dampak negatif yang terjadi seperti 


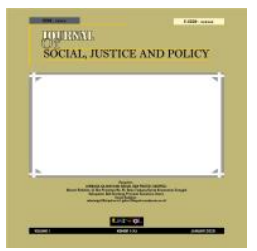

\section{JOURNAL OF SOCIAL, JUSTICE AND POLICY \\ ISSN (ONLINE): 2809-8080}

\section{Volume 1 Number 1 January 2022}

pemerkosaan, kehamilan diluar pernikahan dan kekerasan dalam pacaran. Untuk kekerasan sendiri, tidak jarang hubungan berpacaran diwarnai dengan kasus kekerasan terutama dilakukan oleh laki-laki. Tetapi, masih banyak masyarakat yang tidak tahu adanya kekerasan dalam berpacaran, karena kurangnya informasi dan data dari laporan korban mengenai kekerasan dalam pacaran tersebut. Selain dampak fisik, pacaran bisa mengakibatkan perasaan trauma dalam menjalin hubungan

Kekerasan dalam pacaran (KDP) merupakan tindak kekerasan yang dilakukan dalam hubungan pacaran yang dampaknya dapat menimbulkan luka fisik maupun psikologis atau bisa disebut kekerasan verbal dan nonverbal. Kekerasan verbal adalah kekerasan yang dilakukan secara lisan atau melalui katakata kasar yang bisa menyakitkan hati. Sedangkan nonverbal adalah tidak dengan kata-kata tetapi fisik, ekspresi wajah, intonasi suara, dan kecepatan berbicara. Kekerasan dalam pacaran banyak terjadi pada perempuan ini sering diakibatkan adanya ketimpangan antara laki-laki dan perempuan yang dianut oleh masyarakat luas pada umumnya. Perempuan menurut pendapat laki-laki biasanya dianggap sebagai makhluk yang lemah, penurut, pasif, sehingga menjadi alasan utama terjadinya perlakuan yang semena-mena. Kekerasan dalam pacaran semakin kerap terjadi belakangan ini. Peranan lingkungan social seperti keluarga dan teman memainkan peranan penting dalam mencegah tindak kekerasan dalam berpacaran.

Penelitian Wall (2009) (dalam Mardiah, dkk 2017:30) menjelaskan bahwa kedekatan orangtua memiliki pengaruh yang sangat penting. Pemantauan orangtua muncul sebagai faktor pelindung untuk mengurangi korban dan agresi relasional kekerasan dalam pacaran. Namun dalam penelitian Richards, Branch, dan Ray (2014) (dalam Mardiah, dkk 2017:30), telah dibuktikan bahwa dukungan teman sebaya berhubungan erat dan berpengaruh lebih besar untuk menurunkan tingkat kekerasan dalam pacaran dibandingkan dengan dukungan dari orangtua. Kekerasan dalam pacaran dapat disebabkan karna minimnya pengetahuan tentang pacaran sehingga banyak dari mereka mempunyai pemahaman yang salah. Remaja seringkali menganggap pacaran itu sebagai konsep saling memiliki antara satu sama lain dalam berbagai aspek kehidupan (Hadi, 2002) (dalam Lula An Naafi 2015:3). Terjadinya kekerasan dalam pacaran disebabkan oleh beberapa hal, seperti budaya partiarkhi atau menempatkan laki-laki pada posisi yang lebih unggul dari perempuan. Hasil penelitian lain menyebutkan bahwa penggunaan alkohol juga bisa menyebabkan terjadinya kekerasan dalam pacaran (Wilson, 2014) (dalam Lula An Naafi 2015:3). Faktor lain yang mempengaruhi Kekerasan dalam pacaran (KDP) adalah faktor kepribadian, interpersonal, serta kebiasaan dari keluarganya.

Kekerasan fisik dalam pacaran merupakan salah satu bentuk pelanggaran terhadap hak asasi manusia. Dalam Undang Undang Dasar Tahun 1945 pasal 28 ayat (1) dan ayat (2). Kekerasan dalam pacaran memberikan dampak kepada perempuan terutama secara psikologis biasanya korban merasa sangat marah, jengkel, merasa bersalah, malu dan terhina. Dampak jangka Panjang berupa sikap atau persepsi yang negatif terhadap diri sendiri maupun terhadap laki-laki.

Berdasarkan hal-hal diatas peneliti tertarik untuk mengangkat penelitian ini adanya kekerasan dalam berpacaran ini terjadi pada orang-orang terdekat di lingkungan kampusnya. Dan melihat dari data Kementerian Pemberdayaan Perempuan dan Perlindungan Anak (KPPPA) yang bekerjasama dengan Badan Pusat Statistik (BPS) di media online bahwa semakin meningkatnya kekerasan di Indonesia. Tujuan tulisan ini untuk menggambarkan terjadinya perilaku kekerasan dalam berpacaran di kalangan mahasiswa Universitas Sumatera Utara terutama perempuan. 


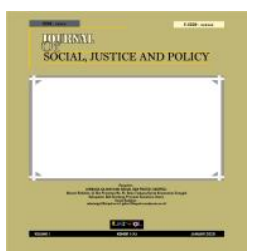

\section{JOURNAL OF SOCIAL, JUSTICE AND POLICY \\ ISSN (ONLINE): 2809-8080}

Volume 1 Number 1 January 2022

\section{Metode}

Penelitian ini tergolong penelitian deskriptif dengan menggunakan pendekatan kualitatif. Lokasi penelitian ini dilakukan di Universitas Sumatera Utara Kecamatan Medan Baru Kota Medan. Informan utama dalam penelitian ini adalah para korban kekerasan dalam berpacaran. Informan tambahan dalam penelitian ini adalah teman dan keluarga. Metode pengumpulan data yang digunakan melalui wawancara, observasi, dokumentasi, dan studi kepustakaan. Analisis data penelitian ini menggunakan metode kualitatif.

\section{Pembahasan}

Pandangan yang lebih luas diungkapkan Poerwandari dalam Achi Sudiarti (2000:11) (dalam Dian Ungki Yunita Dewi, 2008:31), bentuk kekerasan dalam berpacaran meliputi:

1. Kekerasan fisik, yaitu memukul, menampar, mencekik, menendang, melempar barang ke tubuh korban, menginjak, melukai dengan tangan kosong dan sampai pada pembunuhan.

2. Kekerasan psikologis, yaitu berteriak-teriak, mengancam, menyumpah, mengatur, menguntit, memata-matai, dan tindakan lainnya yang menyebabkan rasa takut.

3. Kekerasan seksual, mencakup mengarah ke ajakan atau desakan seksual seperti menyentuh, meraba, mencium, atau melakukan tindakan-tindakan yang tidak dikehendaki korban.

4. Kekerasan ekonomi, yaitu mengambil uang korban, mengatur pengeluaran dari hal sekecilkecilnya dengan maksud mengendalikan tindakan korban, memaksa korban untuk membiayai kebutuhan hidupnya.

Dari pembahasan di atas bahwa Informan Utama I bertahan dalam hubungan yang mendapatkan perilaku kekerasan karena masih sayang, merasa belum di titik capek yang sampai benar-benar ingin selesai tanpa harus kembali lagi, merasa capek dan tidak mudah untuk dekat dan memulai hubungan dengan orang yang baru, kedekatan keluarga saudari EA dengan keluarga MK pacarnya sudah sangat begitu dekat menjadi alasan untuk saudari EA mau kembali karna masih adanya hubungan baik diantara dua keluarga tersebut. sehingga informan tersebut bertahan dalam hubunganwalaupun mendapatkan perilaku kekerasan verbal seperti kekerasan psikologis dan kekerasan Nonverbal seperti kekerasan fisik.

Informan II juga mengalami kekerasan yaitu kekerasan psikologis yang termasuk dalam kekerasan verbal. Yang membuat dia bertahan dengan hubungan yang seperti itu karna ancaman yang pacarnya lakukan terhadapnya sehingga membuat dia takut dan trauma sampai di titik merasa tidak berguna. Untuk Informan utama III bertahan pada hubungan yang seperti itu karena rasa sayangnya terhadap pacarnya, ancaman dia yang selalu ingin membunuh atau pacarnya akan bunuh diri jika hubungannya selesai, dan juga bukan hanya dari ancaman tapi menyakiti fisik informan tersebut.

Berdasarkan hasil penelitian yang dilakukan, jika dibandingkan dengan penelitian yang relevan permasalahan yang di alami di Surabaya, Indonesia secara keseluruhan merupakan permasalahan yang juga dialami mahasiswa di Fakultas Ilmu Sosial dan Politik Universitas Sumatera Utara, yaitu adanya kesamaan kasus yang terjadi dan kurangnya keterbukaan dari korban kekerasan dalam keluar dari permasalahan yang ia hadapi.

Berdasarkan hasil observasi yang terlihat pada Informan utama I terlihat bahwa keadaan fisik dan psikis Informan sangat kuat dalam menerima berbagai pertanyaan dan terlihat konsentrasi dalam mendengarkan pertanyaan dari peneliti. 


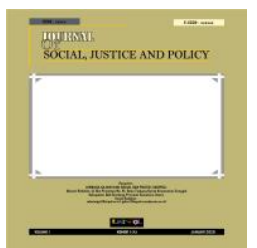

\section{JOURNAL OF SOCIAL, JUSTICE AND POLICY \\ ISSN (ONLINE): 2809-8080}

\section{Volume 1 Number 1 January 2022}

Informan menceritakan cara teman-temannya menyikapi masalah yang dia hadapi. Peneliti melihat Informan juga mendapatkan lingkungan pertemanan yang baik di kampusnya karena mereka sangat membantu Informan dalam memberikan solusi untuk bangkit agar dia secepatnya keluar dari hubungan yang tidak seharusnya di pertahankan dan memberikan dukungan yang positif ketika dia sudah bisa mengakhiri hubungannya. Keadaan ekonomi yang terlihat berkecukupan dan mempunyai keluarga yang sangat peduli ketika melihat Informan yang masih diantar dan dijeput oleh orang tuanya.

Pada Informan Utama II terlihat bahwa keaadan fisik dan psikis sangat lemah. Sebelum masuk ke wawancara Informan terlihat sangat tidak sabar untuk menceritakan apa yang dia alami. Tapi ketika wawancara Informan menjawab seperti tidak konsentrasi dan mengutarakan kata-kata tetapi dalam keadaan melamun seperti pikiran kosong. Keadaan ekonomi terlihat Informan sangat berkecukupan dilihat dari ia mempunyai mobil dan menggunakan berbagai barang yang terlihat mahal. Pilihan informan untuk tidak di kost-kostan karna ia tidak ingin dilarang padahal dengan dia mengendarai mobil atau kendaraan lain tempat tinggalnya masih bisa dijangkau tetapi dia lebih memilih ngekost dengan alasan kepada orang tuanya bahwa dia takut terlambat. Interaksi sosial yang dilakukan Informan terhadap orang lain sangatlah baik dan bertutur kata sopan. Pada saat Informan diberikan pertanyaan, ada satu atau dua pertanyaan yang membuat dia menangis tapi tetap terlihat kuat dan tegar. Dalam keadaan masih diterror oleh pasangannya setelah baru putus, Informan tetap mencoba untuk ringan senyum dan memperlihatkan bahwa masalah ini akan selesai seiring berjalannya waktu.

Sedangkan pada Informan utama III sangat jelas bahwa dia lebih pendiam dan menahan diri untuk tidak menceritakan apa yang dia rasakan ke orang-orang sekitarnya dan dia lebih memilih untuk memendam walaupun pada akhirnya teman-temannya tau tentang apa yang dia alami karna melihat sendiri. keadaan ekonomi Informan ini juga sangat berkecukupan dan mempunyai keluarga yang amat sangat peduli terlihat dari orangtuanya menelpon dan menanyakan dia dimana, dengan siapa, dan mau di jeput jam berapa seperti itu. Sifat pendiam nya dan memilih teman membuat dia beruntung mendapatkan teman dekat yang peduli akan masalah yang dia alami. Keterbatasan yang dialami peneliti selama melakukan penelitian ini yaitu sebagai berikut:

a. Hasil wawancara dari informan utama, informan kunci, dan tambahan hanya dapat diceritakan, tanpa peneliti melihat secara langsung perlakuan kasar yang diterima oleh mahasiswa-mahasiwa tersebut.

b. Peneliti harus ber empati, agar ikut merasakan apa yang dirasakan oleh Informan supaya mendapatkan keterbukaan dari kekerasan yang dialami.

c. Peneliti mempunyai waktu yang singkat dalam melihat kehidupan informan secara langsung karna terhambat pandemi COVID-19 dan tidak adanya kegiatan perkuliahan di kampus.

\section{Kesimpulan}

Berdasarkan hasil penelitian dan pembahasan diatas dapat diketahui bahwa, 1) proses terjadinya kekerasan dalam berpacaran disebabkan oleh beberapa hal yaitu rasa cemburu, rasa ingin memiliki yang berlebihan hingga menuntut harus selalu bersama dia, selingkuh, tidak patuh dan menuruti apa yang selalu diinginkan oleh pacarnya, 2) bentuk-bentuk kekerasan yang dialami dalam berpacaran adalah kekerasan psikologis yang termasuk dalam kekerasan verbal dan kekerasan fisik yang termasuk dalam kekerasan Nonverbal, dan 3) alasan mahasiswa untuk bertahan dalam hubungan yang mengalami kekerasan dalam berpacaran karena adanya rasa takut, sangat cinta, merasa terlanjur 


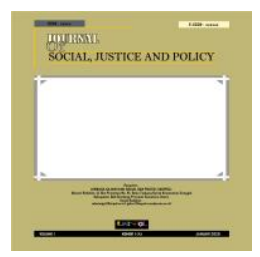

\section{JOURNAL OF SOCIAL, JUSTICE AND POLICY \\ ISSN (ONLINE): 2809-8080}

\section{Volume 1 Number 1 January 2022}

nyaman bahkan terbiasa, perasaan takut gagal lagi dalam hubungan yang baru, malu, dan hubungan yang sudah terjalin lama.

\section{Daftar Pustaka}

Aptia, Elfa. (2017). Pengalaman pada Remaja Perempuan yang Mengalami Kekerasan dalam Pacaran (Dating Violence). Skripsi. Universitas Andalas. Padang.

Dewi Yunita, U, D. (2008). Atas Nama Cinta Studi Kasus tentang Mahasiswa Korban Kekerasan dalam Pacaran. Skripsi. Universitas Negeri Yogyakarta. Yogyakarta.

Erna Mesra, dkk. (2014). Kekerasan dalam Pacaran pada Remaja Putri Di Tangerang. Jurnal Politeknik Kesehatan Kementerian Jakarta III. Vol.2, No.1, 11 Desember 2020.

Mardiah, A., Satriana, D.P., \& Syahriati, E. (2017). Peranan Dukungan Sosial dalam Mencegah Kekerasan dalam Pacaran. Jurnal Psikologi Ulayat. Vol. 4, No.1, 11 December 2020.

Noer, Arienita. (2015). Survei Perilaku Kekerasan dalam Pacaran pada Remaja di Pekanbaru. Skripsi. Fakultas Psikologi. UIN Sultan Syarif Kasim. Riau.

Noviolieta, Christianti. (2013). Kekerasan dalam Pacaran. Skripsi. Fakultas Ilmu Pendidikan. Universitas Negeri Yogyakarta. Yogyakarta.

Rohmah, Silfiatur. (2014). Motif Kekerasan dalam Relasi Pacaran Di Kalangan Remaja Muslim. Jurnal Fakultas Ilmu Sosial. Vol. 2, No.1, 23 Desember 2020.

Shoufia, Aina. (2008). Kekerasan dalam Film Bergenre Horor. Skripsi. Fakultas Ilmu Sosial dan Politik. Universitas Muhammadiyah Malang. Malang.

Undang-Undang Dasar Republik Indonesia Tahun 1945 Pasal 28 Tentang Hak Asasi Manusia 